\title{
Characterization of Danube Swabian population samples on a high- resolution genome-wide basis
}

\author{
Zsolt Bánfai ( $\nabla$ banfai.zsolt@pte.hu ) \\ Department of Medical Genetics, Medical School, University of Pécs \\ Erzsébet Kövesdi \\ Institute of Physiology, Medical School, University of Pécs \\ Katalin Sümegi \\ Department of Biochemistry and Medical Chemistry, Medical School, University of Pécs \\ Gergely Büki \\ Department of Medical Genetics, Medical School, University of Pécs \\ András Szabó \\ Szentágothai Research Centre, University of Pécs \\ Lili Magyari \\ Szentágothai Research Centre, University of Pécs \\ Valerián Ádám \\ Department of Medical Genetics, Medical School, University of Pécs \\ Ferenc Pálos \\ Department of Medical Genetics, Medical School, University of Pécs \\ Attila Miseta \\ Department of Laboratory Medicine, Medical School, University of Pécs \\ Miklós Kásler \\ National Institute of Oncology \\ Béla Melegh \\ Department of Medical Genetics, Medical School, University of Pécs
}

\section{Research Article}

Keywords: genome-wide data, population genetics, Swabians, ethnic group, admixture, haplotype

Posted Date: March 28th, 2022

DOI: https://doi.org/10.21203/rs.3.rs-1407483/v2

License: (c) (1) This work is licensed under a Creative Commons Attribution 4.0 International License. Read Full License 


\section{Abstract \\ Background}

German-derived ethnicities are one of the largest ethnic groups in Hungary, dating back to the formation of the Kingdom of Hungary, which took place at the beginning of the 11th century. Germans came to Hungary in many waves. The most significant immigration wave took place following the collapse of the Ottoman Empire in East-Central Europe which closed the 150-year long Ottoman occupation. To date, there are no comprehensive genome-wide studies investigating the genetic makeup of the Danube Swabians. Here we analyzed 47 Danube Swabian samples collected from elderly Danube Swabian individuals living in the Dunaszekcső-Bár area, Danube side villages in Southwest Hungary. Based on selfdeclaration they did not admix with other ethnic groups for 3-6 succeeding generations. Using Illumina Infinium 720K Beadchip genotype data, we applied allele frequency-based and haplotype-based genome-wide marker data analyses to investigate the ancestry and genetic composition of the collected Danube Swabian samples.

\section{Results}

Haplotype-based analyses like identity by descent and homozygosity by descent analyses show that the investigated Danube Swabians remained isolated from other ethnic groups which was supported by the D-statistics results. According to our results, the investigated Danube Swabian individuals do not possess detectable recent admixture, and our results suggest that their main source of ancestry can be traced back to the region of Germany.

\section{Conclusions}

This is the first analysis of Danube Swabian population samples based on genome-wide autosomal data. Our results establish the basis for conducting further comprehensive research on Danube Swabians and on other German ethnicities of the Carpathian basin, which can help reconstruct their origin, and identify their major archaic genomic patterns.

\section{Background}

The term "Danube Swabians" (also known as "Donauschwaben") is a collective term for the German-speaking ethnicity populating various countries of Southeastern Europe, especially in the valley of the Danube River. While there were German immigration with smaller numbers also in the 12th century, most of them are the descendants of late 18th century German settlers recruited by Austria to repopulate the area and restore agriculture after the defeat of the Ottoman Empire. Danube Swabians can be found in the territory of Hungary, Romania, Serbia, and Croatia.

Hungary has been a multicultural, multiethnic region since the foundation of the former Kingdom of Hungary at the beginning of the 10 th century. Germans form the third largest ethnicity in today's Hungary following the Hungarians and the Romani people. Their estimated number in 2016 was about 178837 people, which is $1.8 \%$ of the total population of Hungary [1].

Germans migrated into the Carpathian basin in multiple waves from several areas [2]. Most of today's German settlements in Hungary were established after the end of the Ottoman occupation of the region. The greatest wave of German immigration began in the 18th century named "the Great Swabian Migration" mostly from the areas of Alsace-Lorraine, Baden, Luxembourg, Pfalz, Saarland (Frankfurt and Mainz), Hesse (Fulda) and Württemberg. The German colonization ended in the first half of the 19th century. The population of Swabian settlements remained isolated until their expulsion in 1946, after World War II. The villages, which were almost exclusively German-inhabited villages earlier, became multiethnic. Most of the Danube Swabians assimilated and merged into the Hungarian society during the 19th-20th century.

The village of Dunaszekcső was first settled by Germans in the 18th century with the inhabitants originating from Tyrol, Silesia, Bamberg, DonauEschingen, Black Forest, Bavaria and Switzerland, Vienna and Saxony. These settlers dealt mainly with agriculture, handicrafts and viticulture [3]. The population of the village in 2018 was 1892 people with an ethnic composition of Hungarian (80\%), German (14\%) and Roma (4\%) [4]. The first written records mention the neighboring Swabian village Bár (Boor, Bor) in 1296. It was settled by Germans in the 1700 s, who established significant vineyards. Most of the settlers came from southern and western Germany (Hesse and Fulda) [3]. The population of the village was 572 people in 2021, with Hungarian, German, and Serbian ethnicities [4].

The aim of our study was to conduct a pilot genome-wide autosomal investigation of Swabian individuals living in the Dunaszekcső and Bár area, who, according to self-declaration and their reconstructed family trees, are not admixed with members of other ethnicities for 3-6 succeeding generations on their ancestries. Allele frequency and haplotype-based population structure, ancestry estimation software along with formal tests of admixture and identity by descent segment analysis methods were carried out on the genome-wide autosomal marker data of the obtained Danube Swabian samples in order to assess their isolated state and the resulting genetic composition.

Page 2/10 


\section{Results}

\section{Population structure and ancestry analysis}

Principal component analysis (PCA) results show that Swabians samples are tightly clustered with each other and are close to other European groups, and Europeans form a completely distinct cluster from South Asians (Fig. 1). South Asians also form a rather tight cluster; however, the plotting of some South Asian samples have a clearly expressed orientation towards Han Chinese and also towards Yoruba. These groups are not shown on the PCA graphs due to the large distances. This orientation cannot be observed in case of the European cluster therefore also not present in the case of Swabian samples. In the European cluster, Swabians are plotting together with West Europeans, like French, Germans and North Italians. Hungarians form a rather distinct cluster from Swabians. South Europeans, like Tuscans, Sardinians, East Europeans, like Russians also form a distinct cluster from Swabians within Europeans. This can be also observed in the case of French Basques, which population are the direct descendants of European hunter-gatherers from the Neolithic mostly unadmixed with Indo-European groups. More information of this PCA using four eigenvectors can be found in the supplemental data (Supplemental Fig. 1).

In the ADMIXTURE analysis, the cross-validation error was the lowest at $\mathrm{K}=5$, therefore the investigated populations are derived most likely from 5 ancestral populations (Fig. 2). The resulting ADMIXTURE graph strengthens the results of PCA and reflects the same relationship of the investigated populations. According to PCA, ancestry proportions of Swabians from the 5 hypothetical ancestral groups are most similar to the West European populations, especially the French, the Germans and the North Italians. There are three major common ancestral groups, the West Europeans (purple), the East Europeans/Middle-Easterns/Central Asians (yellow) and the least significant major common group that can be derived from the South Asian region right next to the Middle East (red). ADMIXTURE analysis results with $\mathrm{K}=2$ to $\mathrm{K}=10$ hypothetical ancestral groups and the calculated cross-validation error values can be found in the supplemental data (Supplemental Figs. 2 and 3).

TreeMix also reflects the same relationships, as the drift parameter is most similar in case of West Europeans to Swabians within the branch consisted of Europeans (Fig. 3). TreeMix was not able to detect any migration events between the investigated populations.

The average pairwise allele frequency differentiation matrix $\left(F_{s t}\right.$ matrix) quantifies the results of PCA and shows that Swabians are similarly close to Hungarians than Germans and French (Table 1).

Table 1

$\mathrm{F}_{\mathrm{st}}$ calculation results

\begin{tabular}{|c|c|c|c|c|c|c|c|c|c|c|c|}
\hline & Swabian & Hungarian & Romanian & German & Adygei & $\begin{array}{l}\text { French } \\
\text { Basque }\end{array}$ & French & $\begin{array}{l}\text { North } \\
\text { Italian }\end{array}$ & Orcadian & Russian & Sardinian \\
\hline Hungarian & 0.001 & & & & & & & & & & \\
\hline Romanian & 0.002 & 0.001 & & & & & & & & & \\
\hline German & 0.001 & 0.000 & 0.002 & & & & & & & & \\
\hline Adygei & 0.010 & 0.009 & 0.006 & 0.009 & & & & & & & \\
\hline FrenchBasque & 0.009 & 0.009 & 0.009 & 0.008 & 0.018 & & & & & & \\
\hline French & 0.001 & 0.001 & 0.002 & 0.001 & 0.009 & 0.007 & & & & & \\
\hline Northltalian & 0.003 & 0.003 & 0.002 & 0.003 & 0.009 & 0.008 & 0.002 & & & & \\
\hline Orcadian & 0.005 & 0.005 & 0.007 & 0.004 & 0.014 & 0.012 & 0.004 & 0.007 & & & \\
\hline Russian & 0.005 & 0.004 & 0.005 & 0.003 & 0.012 & 0.014 & 0.006 & 0.009 & 0.008 & & \\
\hline Sardinian & 0.011 & 0.012 & 0.010 & 0.012 & 0.019 & 0.013 & 0.009 & 0.007 & 0.017 & 0.020 & \\
\hline Tuscan & 0.003 & 0.003 & 0.002 & 0.004 & 0.008 & 0.008 & 0.002 & 0.002 & 0.008 & 0.009 & 0.007 \\
\hline
\end{tabular}

\section{Formal test for assessing relationships}

The 4-population test show that Swabians are strongly connected to West Europeans compared to Hungarians, but pointed out that Hungarians are more closely related to them than East Europeans and South European isolated groups such as the Sardinians (Table 2). Z-scores were effectively 0 at the first setup in case of West Europeans except of North Italians, which was also not significantly negative. We got significantly negative Zscores in case of East and South Europeans with a peak in case of Adygey. The second setup shows similar results. 
Table 2

D-statistic results

\begin{tabular}{|c|c|c|c|c|c|}
\hline Outgroup & Pop1 & Pop2 & Pop3 & D-stat & Z-score \\
\hline W & $X$ & $\mathbf{Y}$ & $\mathbf{Z}$ & & \\
\hline Yoruba & Swabian & Hungarian & German & 0.0000 & -0.051 \\
\hline Yoruba & Swabian & Hungarian & Russian & -0.0050 & -6.857 \\
\hline Yoruba & Swabian & Hungarian & French & 0.0001 & 0.168 \\
\hline Yoruba & Swabian & Hungarian & Adygei & -0.0179 & -19.711 \\
\hline Yoruba & Swabian & Hungarian & Northltalian & -0.0024 & -2.851 \\
\hline Yoruba & Swabian & Hungarian & Sardinian & -0.0030 & -3.385 \\
\hline Yoruba & Hungarian & Swabian & German & -0.0003 & -0.310 \\
\hline Yoruba & Hungarian & Swabian & Russian & -0.0040 & -6.089 \\
\hline Yoruba & Hungarian & Swabian & French & -0.0011 & -2.040 \\
\hline Yoruba & Hungarian & Swabian & Adygei & -0.0181 & -21.647 \\
\hline Yoruba & Hungarian & Swabian & Northltalian & -0.0037 & -4.949 \\
\hline Yoruba & Hungarian & Swabian & Sardinian & -0.0050 & -6.258 \\
\hline
\end{tabular}

\section{Detailing relationships using haplotype-based analyses}

The average identical by descent (IBD) share of Swabians was the lowest with Hungarians (0.65), French Basques (0.75), Adygey (1.09) and Sardinians (1.17) (Fig. 4a). Highest IBD of Swabians was the highest with Germans, which was 3.94 and with Romanians with an average share of 2.87. This analysis showed also that ancestry of Swabians can be mostly derived from Germans and other West Europeans are a much less important source of ancestry. The high average share with Romanians is intriguing and can be the result that Romania has significant German ethnicity which are the Transylvanian Saxons, and other German ethnic groups e.g. Swabians as we stated before.

Average length and number of IBD segments show that Hungarians are very similar to Germans in this regard, which implies that the huge difference in average sharing comes from the individual inconsistency of the number and length of shared IBD segments between Hungarians and Swabians suggesting only a slight and sporadic admixture between these two (Fig. 4b). The average genome-wide autozygosity is higher or similar than most investigated populations, but not outstanding, which might indicate a moderate isolation and a low inbreeding rate (Fig. 4c). However, since the average IBD share of Swabians with Hungarians were low, their admixture can hardly be accounted for Hungarians, they could have admixed rather with other Swabians living on neighboring settlements or with other ethnic groups of the area. This phenomenon needs further investigations.

\section{Discussion}

Our population structure analysis with PCA pointed out that Swabians are the closest to West-Europeans and clusters rather separately from the Hungarians, which could suggest that admixture of the investigated Swabian group with Hungarian population was not substantial. ADMIXTURE showed that the populations included in the study can be traced back to 5 ancestry sources from which there are 3 ancestral groups as major sources, which are mainly West and East European derived ancestries, with a less significant ancestry component from the Western part of the South Asian region. According to ADMIXTURE, the share from these ancestries in case of Swabians and Hungarians are quite similar, which was shown also by the similar $\mathrm{F}_{\mathrm{st}}$ values. With a third ancestry estimation method, which also utilizes a maximum likelihood method as the algorithm of ADMIXTURE, the genetic differences between Hungarians and Swabians became more pronounced and mirrored the results of PCA, Swabians are closer to West Europeans rather than Hungarians.

Using formal tests of admixture, we further investigated our observation that Swabians and Hungarians might not admixed with each other significantly, which proved to be correct, since D-statistics pointed out that Swabians are significantly closer not only to Germans rather to West Europeans in general than to Hungarians. However, it also showed that Hungarians are closer to Swabians than South or East Europeans, which can be the simply because East-Central Europe is closer to West Europe than the former two areas of the continent, East-Central Europe and West Europe are neighboring regions.

Investigating the source of ancestry of the Swabian group calculating the average pairwise IBD share between them and other investigated populations showed that the most important source of ancestry indeed come from Germany, and Hungarians have little to do with the lineage of Swabians, since their IBD share was significantly low West European groups other than Germans have little to do with Swabians ancestry, since 
their IBD sharing values were less or similar that of East Europeans, e.g. the Russians, except North Italians, a group which is geographically at a similar distance like Germans. Interestingly, Romanians also show a more significant ancestry source in Swabians. Since Germans of Romania are one of the most significant ethnic groups of the region, it is a possibility that there are several Romanian individuals in the data with substantial German ancestry. This should be further investigated using more carefully selected Romanian samples. The average value of shared IBD length and average number of shared IBD segments are very similar in case of Hungarians and Germans which could suggest that Hungarians are very heterogeneous in terms of German ancestry components.

\section{Conclusions}

According to the average genome-wide autozygosity of Swabians, they are a moderately isolated population compared to other ethnic groups, however, according to our analyses, they did not admix substantially with the local Hungarian population.

The Danube Swabian population of Dunaszekcső and Bár are clearly of German origin showing little admixture with Hungarians. Their culturally and genetically isolated lifestyle is well observable and well-detectable applying genome-wide autosomal marker data. These carefully selected samples are from Swabian individuals born in the first half of the 20th century when ethnic self-awareness and the preservation of their specific culture and heritage were part of their everyday life. In the late 20th and in the 21 st centuries these traditions became less and less commonplace shrinking back to special cultural events rather than being an everyday lifestyle, and the Swabian population began also to mingle more significantly with other surrounding ethnicities. Their lives also shifted towards cities which further facilitated the continuous decline of the population of traditional Swabian villages. These processes render our Swabian sample collection invaluable and should be the basis of further, much more detailed investigations regarding the German derived ethnicities of the Carpathian basin.

\section{Methods}

\section{Samples and applied data}

In this study we examined samples from 47 Danube Swabian individuals with well-documented family history dating back to 3-6 succeeding generations with unadmixed Swabian ancestries supported by self-declaration-based family history and the resulting pedigree trees. The Danube Swabian individuals live in the villages of Dunaszekcső and Bár which can be found along the Danube River in Southwest Hungary. 29 samples are from Dunaszekcső and 18 samples were collected from the village of Bár. The Swabian population of these villages remained mostly isolated from other ethnicities until today, providing an opportunity to study their genetic makeup and relationship with other major Eurasian groups.

DNA was extracted from ethylenediaminetetraacetic acid (EDTA)-anticoagulated whole blood and was genotyped on the Illumina Infinium Global Screening Array Beadchip platform which contains 725831 single-nucleotide polymorphisms (SNPs). Isolation, genotyping and preliminary quality control of the samples was carried out by the third-party service provider Human Genomics Facility (HUGE-F) in the Netherlands at the University of Rotterdam. Quality control and data preparation of the marker data was carried out domestically applying in-house scripts and the PLINK1.9 and 2.0 software packages $[5,6]$. The data was filtered using the Hardy-Weinberg equilibrium tests, and additionally, SNPs with missing genotypes were removed from the dataset using PLINK with the 'geno' flag applying a threshold value of 0.1 . All Swabian individuals passed these tests and 665 073 SNPs remained in the Swabian dataset.

This study belongs to a series of investigations that were approved by the National Ethics Board (ETT TUKEB), and by Regional Ethics Committee of Pécs and follows the principles expressed in the Declaration of Helsinki.

Genome-wide autosomal marker data from other open genotype databases was also considered and applied in the study. We used the Human Genome Diversity Project (HGDP) dataset openly available from the server of Stanford University and also applied datasets from the open genomewide marker data repository of the Estonian Biocentre [7-10]. Mainly populations from the European, Caucasus and South Asian regions were applied from the HGDP dataset, however, for outgroup purposes we also considered the Uyghurs, Han Chinese, and Yoruba. Estonian Biocentre populations included Hungarians, Romanians and Germans.

\section{Principal Component Analyses based population structure analysis}

Population structure analysis along with fixation index $\left(\mathrm{F}_{\mathrm{st}}\right)$ matrix computation were achieved using the SMARTPCA software of the EIGENSOFT 6.01 package [11]. A merged dataset of Swabian samples, HGDP populations and Estonian Biocentre data was analyzed with SMARTPCA. Included HGDP populations were French, French Basques, Orcadians, North Italians, Sardinians, Tuscans, Russians, Adygey, Balochi, Brahui, Burusho, Hazara, Kalash, Makrani, Pashtun, Sindhi, Uyghurs, Han Chinese, Yoruba, and Hungarians, Romanians and Germans from the Estonian data were also used. The dataset contained $n=601$ individuals and 110733 SNPs. SNPs with strong background linkage disequilibrium (LD) was also pruned out with the 'indep-pairwise' command of PLINK1.9 setting the $r^{2}$ threshold to 0.3 . It is necessary before the analyses due to strong background LD can bias the PCA method, but also expectation maximization-based ancestry estimation algorithms. After the pruning process, 80056 SNPs remained in our merged dataset. We used SMARTPCA with default settings, the $\sigma$-threshold was set to 6.0.

\section{Maximum likelihood method-based ancestry estimation}


Ancestry estimation was carried out with the ADMIXTURE 1.22 algorithm which is a maximum likelihood estimation method using an expectation maximization approach [12]. The correct number of hypothetical ancestral populations (K) were calculated applying $\mathrm{K}$ values of 2 to 10 and crossvalidation was also performed in order to find the best fitting $\mathrm{K}$ for the relationship of our investigated populations.

TreeMix was also applied along with ADMIXTURE analysis to better describe the relationship of these populations in a maximum-likelihood treebased manner in addition to the stacked column styled ancestry estimation [13]. The size of the SNP blocks (-k flag) was set to 1000 and we also set the algorithm to seek for 1-6 migration events in the data through multiple runs. For these investigations, the same pruned dataset was used that was created for PCA.

\section{Formal test of admixture}

In order to test the relationship of Swabians and other investigated populations, we utilized a formal test of admixture, the 4-population test. The qpDstat program from the ADMIXTOOLS 4.1 package was used for this purpose, and as its name suggests, this test was implemented here as Dstatistics [14]. We tested the unrooted phylogenetic trees containing Yoruba, Swabians, Hungarians and various European and Caucasus region populations, Germans, Russians, French, North Italians, Sardinians and Adygey. The setups of the $((\mathrm{W}, \mathrm{X})(\mathrm{Y}, \mathrm{Z}))$ unrooted trees were the following:

((Yoruba, Swabians)(Hungarians, Europeans)) and ((Yoruba, Hungarians)(Swabians, Europeans)). This test intended to show us the relationship of Swabians to the Hungarian host population, to the Germans and to various European populations. For these calculations, we used the unpruned version of the previously created dataset.

\section{Identical by descent and homozygous by descent analyses}

For assessing the sources of ancestry in the investigated Swabian samples, we implemented here the Refined IBD algorithm of Beagle 4.1 [15]. The software seeks in phased haplotype data for IBD segments between all pairs of individuals, which shows us the relative share of one population in the ancestry of the investigated population. Before the analysis, the data was converted according to the needs of the software using the PLINK1.9 software. The major alleles were set as A1 allele and the dataset was converted to Variant Call Format 4.1 with the PLINK/SEQ software [16]. The minimum segment length was set to 3 centiMorgan, the IBD trim parameter value was 10 . The IBD scale parameter was calculated with the $\sqrt{n / 100}$

recommended formula since our data contained more than 400 individuals [15]. Using the inferred IBD segment data, we calculated an average pairwise IBD sharing between Swabians and various populations with the following formula according to Atzmon et al.:

Average pairwise IBD sharing $=\frac{\sum_{i=1}^{n} \sum_{j=1}^{m} I B D_{i j}}{n \cdot m}$

$I B D_{i j}$ is the length of the IBD segment shared between individuals $i$ and $j$. The $n$ and $m$ are the number of individuals in the groups I and $J$ [17].

We also calculated the average number and average length of IBD segments between Swabians and the investigated various populations.

Besides IBD segments, Refined IBD simultaneously detects homozygous by descent (HBD) segments, which allows us also to infer the genomewide autozygosity of respective populations. This can imply the degree of isolation and degree of inbreeding of these groups. Therefore, average length and number of HBD segments were also calculated.

\section{List Of Abbreviations}

EDTA ethylenediaminetetraacetic acid

HBD homozygous by descent

HGDP Human Genome Diversity Project

IBD identical by descent

LD linkage disequilibrium

PCA principal component analysis

SNP single-nucleotide polymorphism

\section{Declarations}

Ethics approval and consent to participate 
This study belongs to a series of investigations that were approved by the National Ethics Board (ETT TUKEB), and by Regional Ethics Committee of Pécs and follows the principles expressed in the Declaration of Helsinki. The participants gave their written informed consent to participate in this study. They all got personal verbal information prior their signed consent.

\section{Consent for publication}

Not applicable.

\section{Availability of data and materials}

All data generated or analysed during this study are included in this published article and its supplementary figures. All analysed datasets are available in public online repositories, except the Danube Swabian data which according to the Hungarian Human Genetics Act 2008/XXI, cannot be uploaded to a public online database, but can be obtained upon reasonable request via e-mail from the corresponding authors.

\section{Competing interests}

The authors declare that they have no competing interests.

\section{Funding}

This study was supported by the National Scientific Research Program (NKFI) K 138669, by the Institute of Hungarian Research, Budapest, Hungary, by the Human Resources Development Operational Program, Ministry of Human Resources, Hungary and by the Medical School of University of Pécs; EFOP-3.6.1-16-2016-00004.

\section{Authors' contributions}

All authors have materially participated in this work. ZB, EK, KS conceived and designed the investigations, ZB, GB, AS, VA evaluated and interpreted the results of the tests carried out. EK, FP, KS, LM, VA contributed to the data collection and genotyping. ZB, EK, KS, LM co-wrote the manuscript and $\mathrm{BM}, \mathrm{AM}, \mathrm{MK}$ revised the initial draft of the manuscript. All authors read and approved the final manuscript.

\section{Acknowledgements}

We are thankful to the individuals who provided blood samples for this research work.

The present scientific contribution is dedicated to the 650th anniversary of the foundation of the University of Pécs, Hungary.

\section{References}

1. Lajtai M. Nemzetiségi viszonyok és a statisztikai adatgyűjtés Magyarországon [Ethnic relations and statistical data collection in Hungary]. Statisztikai Szemle. 2020;98:547-72.

2. Senz JV. Geschichte der Donauschwaben. 7th ed. Amalthea; 1993.

3. Bezerédy G. Dunaszekcső és Bár története. Baranya Megyei Levéltár; 1975.

4. Belügyminisztérium Nyilvántartások Vezetéséért Felelős Helyettes Államtitkárság. Magyarország állandó lakossága 2021. január 1-jén [The stationary population of Hungary on January 1, 2021] [Internet]. Belügyminisztérium Nyilvántartások Vezetéséért Felelős Helyettes Államtitkárság; 2021. Available from: https://www.nyilvantarto.hu/hu/statisztikak?stat=kozerdeku

5. Purcell S, Neale B, Todd-Brown K, Thomas L, Ferreira MA, Bender D, et al. PLINK: a tool set for whole-genome association and population-based linkage analyses. American journal of human genetics. 2007;81:559-75.

6. Chang CC, Chow CC, Tellier LC, Vattikuti S, Purcell SM, Lee JJ. Second-generation PLINK: rising to the challenge of larger and richer datasets. Gigascience. 2015;4:7.

7. Cavalli-Sforza LL. The Human Genome Diversity Project: past, present and future. Nature Reviews Genetics. 2005;6:333-40.

8. Rosenberg NA, Mahajan S, Ramachandran S, Zhao C, Pritchard JK, Feldman MW. Clines, clusters, and the effect of study design on the inference of human population structure. PLoS Genet. 2005;1:e70.

9. Behar DM, Metspalu M, Baran Y, Kopelman NM, Yunusbayev B, Gladstein A, et al. No evidence from genome-wide data of a Khazar origin for the Ashkenazi Jews. Hum Biol. 2013;85:859-900.

10. Yunusbayev B, Metspalu M, Metspalu E, Valeev A, Litvinov S, Valiev R, et al. The genetic legacy of the expansion of Turkic-speaking nomads across Eurasia. PLoS Genet. 2015;11:e1005068.

11. Patterson N, Price AL, Reich D. Population structure and eigenanalysis. PLoS genetics. 2006;2:e190.

12. Alexander DH, Novembre J, Lange K. Fast model-based estimation of ancestry in unrelated individuals. Genome research. 2009;19:1655-64.

13. Pritchard JK, Stephens M, Donnelly P. Inference of population structure using multilocus genotype data. Genetics. 2000;155:945-59.

Page $7 / 10$ 
14. Patterson N, Moorjani P, Luo Y, Mallick S, Rohland N, Zhan Y, et al. Ancient admixture in human history. Genetics. 2012;192:1065-93.

15. Browning BL, Browning SR. A fast, powerful method for detecting identity by descent. Am J Hum Genet. 2011;88:173-82.

16. Purcell S. PLINK/SEQ: A library for the analysis of genetic variation data. [Internet]. 2014. Available from: https://atgu.mgh.harvard.edu/plinkseq

17. Atzmon G, Hao L, Pe'er I, Velez C, Pearlman A, Palamara PF, et al. Abraham's children in the genome era: major Jewish diaspora populations comprise distinct genetic clusters with shared Middle Eastern Ancestry. American journal of human genetics. 2010;86:850-9.

\section{Figures}

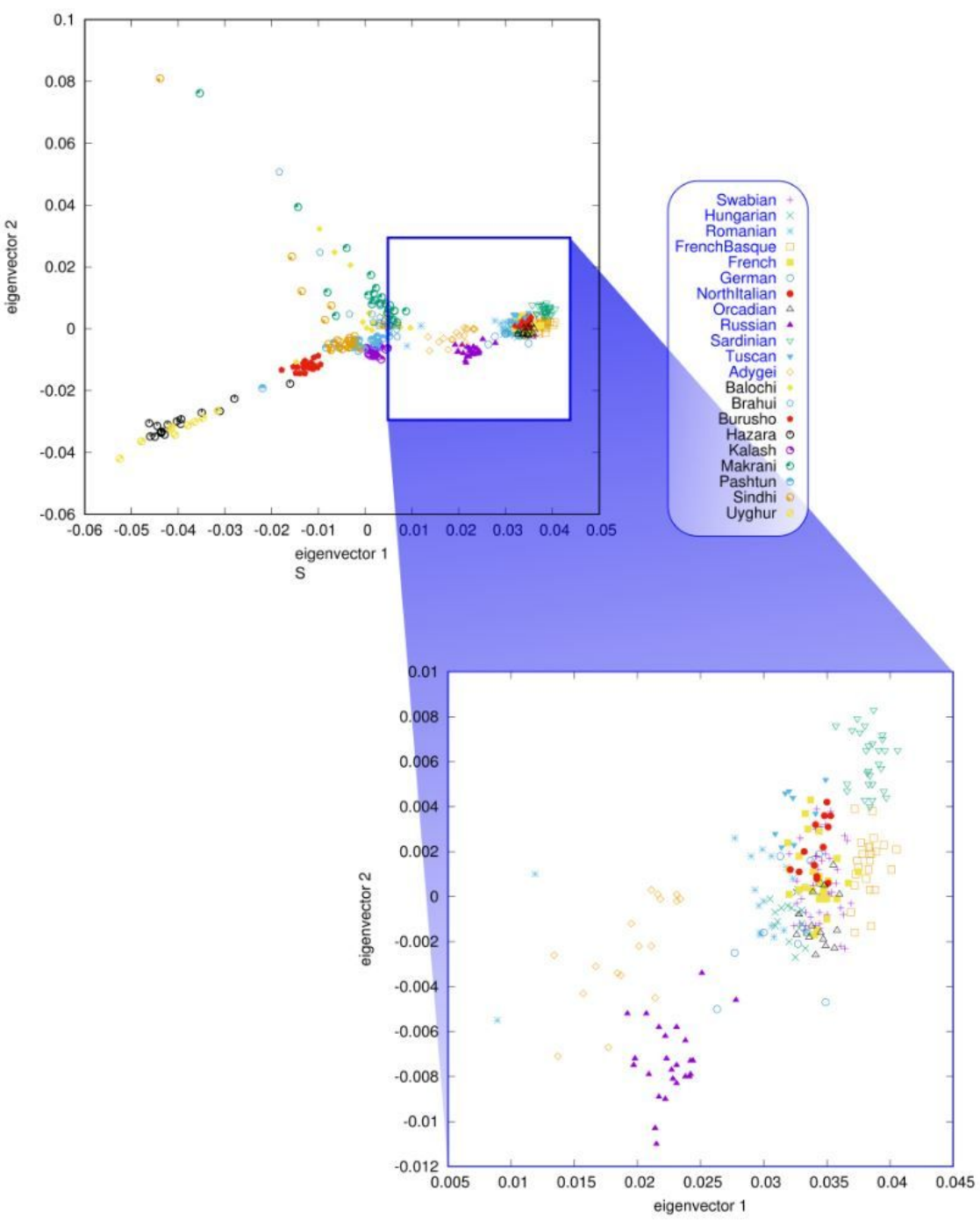

\section{Figure 1}

PCA results of Swabians and investigated populations plotted to the first two principal components. Eigenvalues of eigenvectors 1 and 2 were 18.602 and 12.090 , respectively. 


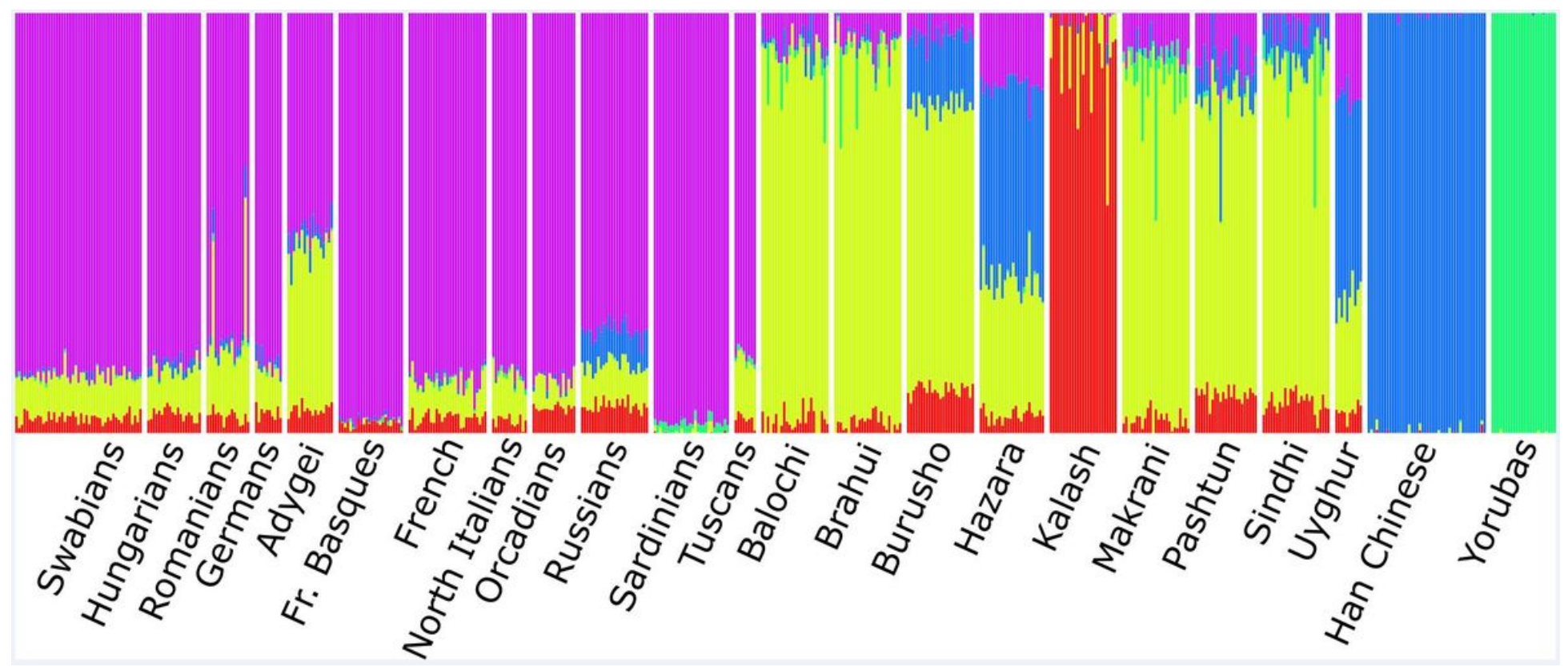

Figure 2

ADMIXTURE analysis results of Swabians and investigated Eurasian populations with $\mathrm{K}=5$.

a)

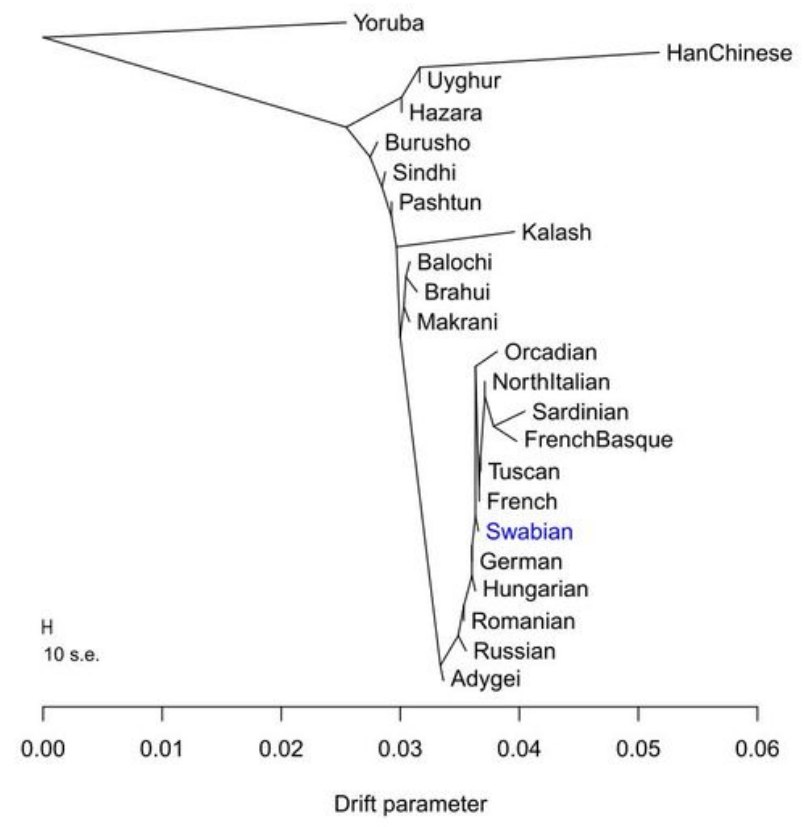

b)

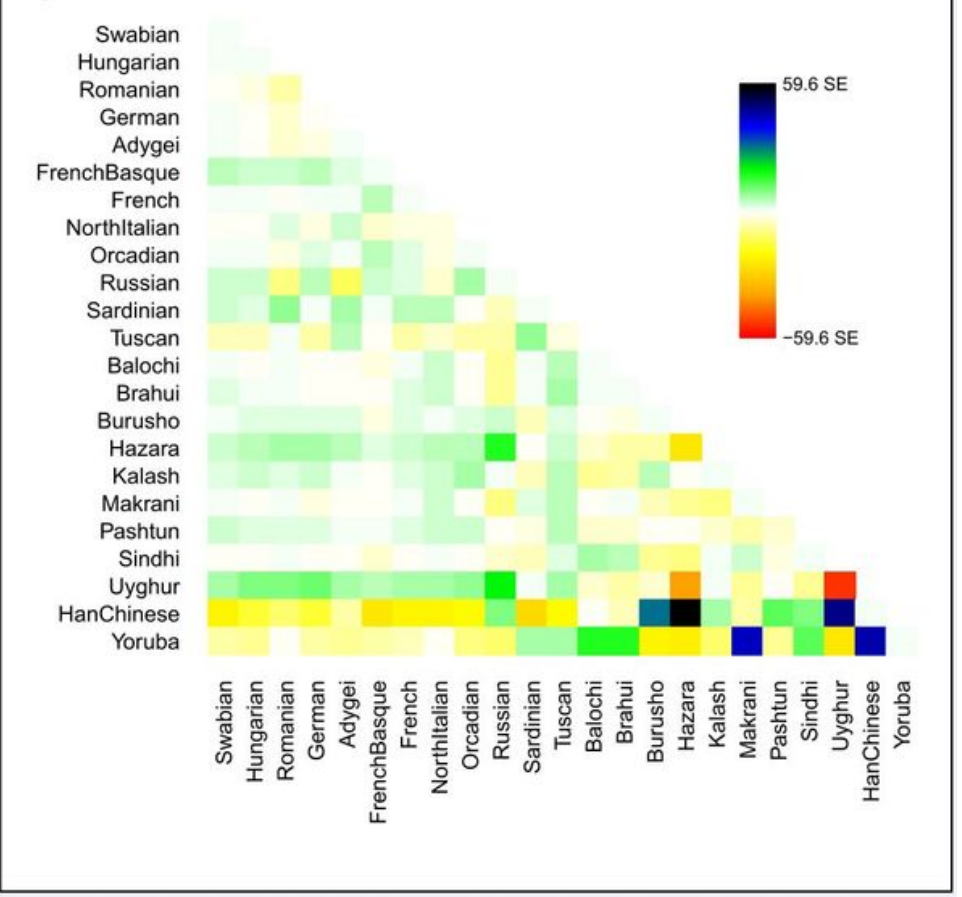

Figure 3

TreeMix analysis. (a) The calculated maximum-likelihood tree, and (b) Standard error visualization using residual fitting. 

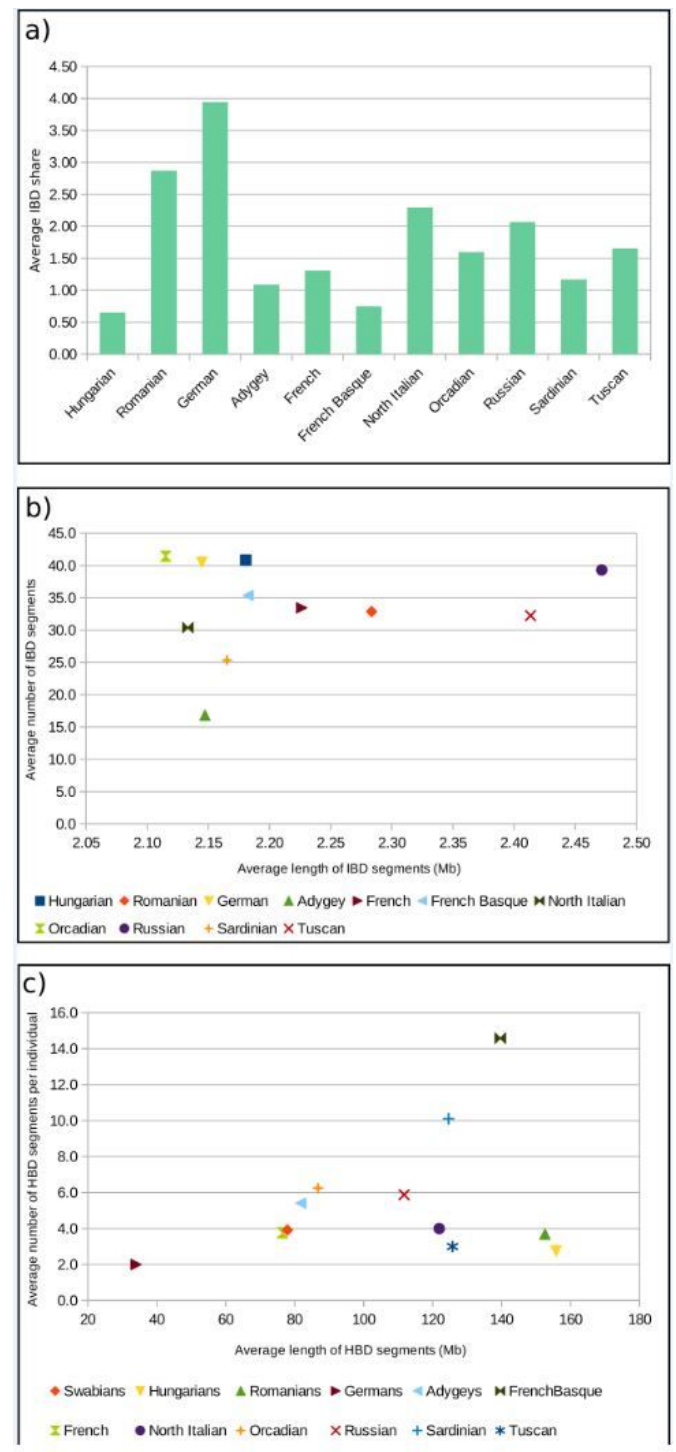

Figure 4

Results of haplotype-based investigations. (a) Average pairwise IBD sharing results, (b) Average length and number of shared IBD segments between Swabians and other investigated groups, (c) Average genome-wide autozigozity calculations of investigated populations.

\section{Supplementary Files}

This is a list of supplementary files associated with this preprint. Click to download.

- SupplementalFigure1.pdf

- SupplementalFigure2.pdf

- SupplementalFigure3.pdf 